\title{
Comparison of the ability of the shock index, modified shock index and age shock index to predict mortality in geriatric patients with COVID-19 pneumonia
}

\author{
D.Davut Tekyol ${ }^{1}$, Nihat Müjdat Hökenek ${ }^{2}$ \\ ${ }^{1}$ Haydarpaşa Numune Education and Research Hospital, Department of Emergency Medicine, İstanbul, Turkey \\ ${ }^{2}$ Dr. Lütfi Kurdar City Hospital, Department of Emergency Medicine, İstanbul, Turkey
}

Cite this article as: Tekyol D, Hökenek NM. Comparison of the ability of the shock index, modified shock index and age shock index to predict mortality in geriatric patients with COVID-19 pneumonia. J Health Sci Med 2021; 4(5): 634-638.

\begin{abstract}
Introduction: A prognostic measure is urgently needed to predict the severity and mortality of the disease at an early stage in elderly patients with COVID-19 pneumonia. We aimed determine the shock, modified shock and age shock indexes in the early prediction of mortality in advanced-age patients with COVID 19 pneumonia.

Material and Method: The study included patients over 65 years of age with COVID-19 pneumonia confirmed with a positive RT-PCR test. All three indexes were calculated for all the included patients. The ROC analysis was used to determine the predictive values of the indexes in determining mortality.

Results: After evaluating the inclusion and exclusion criteria, the study was completed with a total of 134 patients. It was found that the shock index and age shock index did not statistically significantly differ in predicting mortality $(\mathrm{p}=0.23$ and $\mathrm{p}=0.06$, respectively). In the ROC analysis of the modified shock index in predicting mortality, the area under the curve was 0.658 (95\% CI $0.572-0.738)$ and the Youden index was 0.35 ( $\mathrm{p}=0.02$ ). Cases with higher modified shock index values were found to be 86 times more likely to result in mortality than those with lower values.

Conclusion: The modified shock index is a fast, simple and effective method that can be used to predict mortality during triage in the emergency department in patients aged over 65 with COVID-19 pneumonia confirmed by RT-PCR and tomography.
\end{abstract}

Keywords: Age shock index, Coronavirus, COVID-19, modified shock index, pneumonia, shock index

\section{INTRODUCTION}

The COVID-19 pandemic, which started in December 2019 and still continues its effect across the world, remaining a serious global health problem. Advanced age alone is a risk factor for mortality in patients with COVID-19 pneumonia in elderly patients, COVID-19 pneumonia can quickly lead to acute respiratory distress syndrome and other serious complications (1). Acute respiratory distress syndrome (ARDS) that is unresponsive to treatment can lead to multi-organ failure and death. Therefore, early diagnosis and timely treatment are vital in critically ill patients. In this sense, a prognostic measure is urgently needed to predict the severity and mortality of the disease at an early stage in elderly patients with COVID-19 pneumonia. A simple, inexpensive, fast predictive method that can be evaluated especially at the time of initial presentation to hospital can contribute to reducing mortality. Thus, the clinician can take more aggressive approaches while evaluating treatment protocols and prevent mortality.

The shock index (SI) is a rate that can be easily calculated based on blood pressure and pulse measurements. It basically consists of heart rate/systolic blood pressure value (2). Although it was first used to determine the degree of hypovolemia in cases of hemorrhagic and septic shock, today it is also used as an assessment scale in all types of systemic conditions in which tissue perfusion is impaired (3-6). SI has been found to have a particularly strong association with the left ventricular stroke volume and cardiac output (2). SI has also been reported as an independent risk factor of six-week mortality related to community-acquired pneumonia (7). 
The modified shock index (MSI) is found by dividing the pulse by the mean arterial pressure, and the age shock index (ASI) is obtained by multiplying age and SI. These two derivations were produced considering the theoretical contribution of diastolic blood pressure and age to SI; however, MSI has been suggested to be a better marker than SI in some studies conducted in the emergency department (ED) $(8,9)$. In patients with sepsis, a strong relationship has been observed between myocardial dysfunction and mortality (10). This situation is expected and can be explained by the mean arterial pressure having proven itself as a better marker than systolic or diastolic blood pressure value in terms of organ perfusion while evaluating fluid resuscitation and vasopressor requirement in critically ill patients $(11,12)$.

We did not find any published studies concerning the predictive ability of SI, MSI and ASI for mortality in geriatric patients with COVID-19 pneumonia. Therefore, in the current study

our primary aim was to compare the ability of these three indexes to predict mortality in the geriatric patient population with COVID-19 infection. We considered that taking advantage of these indexes, which can be easily measured at the bedside without any wait, can contribute to treatment strategies and mortality prevention in this disease presenting with high mortality at advanced ages. Our secondary aim was to evaluate the superiority of these indexes over each other and explore the relationship of blood test results, vital signs and comorbidities at the time of presentation with mortality.

\section{MATERIALS AND METHODS}

This study was approved by Haydarpaşa Numune Education and Research Hospital Clinical Researches Ethics Committee (Date: 01.03.2021, Decision No: 2021/ $\mathrm{KK} / 78$ ). All procedures were carried out in accordance with the ethical rules and the principles of the Declaration of Helsinki.

This study was planned retrospectively and observationally. Patients who presented to ED due to COVID 19 pneumonia and hospitalized between March 15, 2020 and February 1, 2021 were included in the study. The institutional review board approved the analysis and issued a waiver of consent.

All patients over the age of 65 who were admitted to the ED with COVID-19 complaints, who had oropharyngeal/ nasopharyngeal swabs, and who hospitalized between March 1, 2020 and February 1, 2021 were included in the study. Patients whose reverse transcriptase polymerase chainr eaction (RT-PCR) test results were negative and whose ASI, SI and MSI could not be calculated were excluded from the study.
Data were collected from electronic medical hospital records. Data collected included age, sex, vital signs [body temperature, heart rate (HR), systolic blood pressure (SBP), diastolic blood pressure (DBP), respiratory rate (RR), mean arterial pressure (MAP), blood oxygen saturation (spO2), body temperature (Temp)] and ASISI-MSI. ASI defined as age multiplied by SI. SI was calculated as the ratio of $\mathrm{HR}$ to $\mathrm{SBP}(\mathrm{SI}=\mathrm{HR} / \mathrm{SBP})$. MAP was calculated as follows: $\mathrm{MAP}=[\mathrm{SBP}+(2 \times \mathrm{DBP})] / 3$. The MSI was calculated as the ratio HR to MAP (MSI= HR/MAP). The formulas were calculated using the vital findings at the time of first admission to the ED.

The primary outcome was in-hospital mortality. The secondary outcome was the superiority of the these indexes to each other and their relationship with comorbidities and blood test results.

Statistical analyses were performed using SPSS v. 19.0 for Windows and Med Calc software packages. Descriptive criteria were presented as mean and standard deviation, median and minimum-maximum values, and percentage distribution. The compliance of the data with normal distribution was checked using the Kolmogorov-Smirnov test. The receiver operating characteristic (ROC) analysis was used to determine the predictive values of the three indexes in mortality. The method described by Delong et al. was used to compare the ROC curves of the indexes. $\mathrm{p}<0.05$ was taken as the level of significance.

\section{RESULTS}

After performed the inclusion and exclusion criteria, the study was completed with 134 patients. The demographic data, vital signs, blood test results and index values of the patients are summarized in Table 1. The patients that were survivors (survivors group) and those that died (nonsurvivors group) were compared in relation to various data. As a result of the statistical analysis, the mean age, body temperature, pulse, neutrophil count, D-dimer, ferritin, SI, MSI and ASI were statistically significantly higher in the non-survivors group than in the survivors group, and the mean saturation and lymphocyte levels of the former were statistically significantly lower compared to the latter (Table 1).

The groups were compared with the chi-square test in terms of comorbidity distributions. As a result of the analysis, no statistically significant difference was found between the groups in comorbidity distributions (Table 2). In the ROC analysis for mortality prediction, the area under the curve (AUC) was 0.581 [95\% confidence interval (CI): 0.493-0.666) and the Youden index was 0.23 for SI. In the same analysis for ASI, AUC was calculated as 0.623 (95\% CI: $0.535-0.705)$ and the 
Youden index as 0.26. Accordingly, SI and ASI did not have statistically significant value in predicting mortality $(\mathrm{p}=0.23$ and $\mathrm{p}=0.06$, respectively). In contrast, the ROC analysis for MSI in the prediction of mortality showed that the AUC value was 0.658 (95\% CI: $0.572-0.738$ ) and the Youden index was 0.35 (Figure 1). Thus, MSI was a statistically significant parameter in mortality prediction $(\mathrm{p}=0.02)$. When the cut-off value of MSI in determining mortality was taken as 1.07 , it had $55.6 \%$ sensitivity, $79.4 \%$ specificity, 38.9 positive predictive value, and 86.7 negative predictive value (Table 3 ).
Table 2. Comparison of comorbidities between the discharged and mortality groups

\begin{tabular}{|lccc|}
\hline & $\begin{array}{c}\text { Survivors } \\
\mathbf{n}(\%)\end{array}$ & $\begin{array}{c}\text { Non-survivors } \\
\mathbf{n}(\%)\end{array}$ & $\begin{array}{c}\text { p } \\
\text { value }^{*}\end{array}$ \\
\hline Diabetes mellitus & $51(47.7)$ & $12(44.4)$ & .77 \\
Hypertension & $82(76.6)$ & $19(70.4)$ & .50 \\
Coronary artery disease & $22(20.6)$ & $3(11.1)$ & .26 \\
Asthma & $5(4.7)$ & $3(11.1)$ & .21 \\
COPD & $22(20.6)$ & $4(14.8)$ & .50 \\
Chronic heart failure & $8(7.5)$ & $3(11.1)$ & .54 \\
Chronic kidney failure & $12(11.2)$ & $5(18.5)$ & .31 \\
Other & $25(23.4)$ & $11(40.7)$ & .07 \\
\hline${ }^{*}$ Chi-square test, COPD: Chronic obstructive pulmonary disease \\
\hline \multicolumn{4}{l}{} \\
\hline
\end{tabular}

Table 1. Demographic characteristics, clinical and shock index results of the discharged and mortality groups

\begin{tabular}{|c|c|c|c|c|}
\hline & $\begin{array}{c}\text { Total Mean } \pm \text { SD } \\
\text { Median }(\min -\max ) \mathbf{n}(\%)\end{array}$ & $\begin{array}{l}\text { Survivors Mean } \pm \text { SD } \\
\text { Median }(\min -\max ) \mathbf{n}(\%)\end{array}$ & $\begin{array}{l}\text { Non-survivors Mean } \pm \text { SD } \\
\text { Median }(\min -\max ) \mathbf{n}(\%)\end{array}$ & p value \\
\hline Age,years & $\begin{array}{c}75.1(7.4) \\
74(65-97)\end{array}$ & $\begin{array}{c}74.2(7.1) \\
73(65-97)\end{array}$ & $\begin{array}{l}78.3(7.7) \\
77(67-97)\end{array}$ & $.01^{\mathrm{a}}$ \\
\hline $\begin{array}{l}\text { Gender } \\
\text { Male } \\
\text { Female }\end{array}$ & & $\begin{array}{l}58(76.3) \\
49(84.5)\end{array}$ & $\begin{array}{l}18(23.7) \\
9(15.5)\end{array}$ & $.24^{\mathrm{b}}$ \\
\hline Body Temperature, ${ }^{\circ} \mathrm{C}$ & $\begin{array}{c}37.0(0.9) \\
36.7(35-40.5)\end{array}$ & $\begin{array}{c}36.6(3.3) \\
36.6(35.0-39.5)\end{array}$ & $\begin{array}{c}37.4(1.2) \\
36.8(36.0-40.5)\end{array}$ & $.03^{\mathrm{a}}$ \\
\hline Pulse, beat/min & $\begin{array}{c}84.9(16.7) \\
84(54-120)\end{array}$ & $\begin{array}{c}84.5(13.5) \\
82.5(54-120)\end{array}$ & $\begin{array}{l}92.5(15.5) \\
90(60-120)\end{array}$ & $.006^{\mathrm{a}}$ \\
\hline Systolic blood pressure, $\mathrm{mmHg}$ & $\begin{array}{l}128.9(20.2) \\
130(80-170)\end{array}$ & $\begin{array}{c}129.1(22.3) \\
130.0(80-170)\end{array}$ & $\begin{array}{c}124.7(23.5) \\
126.0(80-168)\end{array}$ & $.29^{\mathrm{a}}$ \\
\hline $\begin{array}{l}\text { Diastolic blood pressure, } \\
\mathrm{mmHg}\end{array}$ & $\begin{array}{c}73.6(14.2) \\
70(40-114)\end{array}$ & $\begin{array}{c}74.1(14.1) \\
70.0(49-114)\end{array}$ & $\begin{array}{c}71.5(14.9) \\
70.0(40-100)\end{array}$ & $.72^{\mathrm{a}}$ \\
\hline Saturation $\mathrm{O}_{2}$ & $\begin{array}{c}93.8(4.6) \\
95.5(77-100)\end{array}$ & $\begin{array}{c}97.8(3.7) \\
96.0(80-100)\end{array}$ & $\begin{array}{c}89.9(5.8) \\
90.0(77-98)\end{array}$ & $.001^{\mathrm{a}}$ \\
\hline Leukocyte count & $\begin{array}{c}8.7(4.8) \\
8.4(0.5-29.0)\end{array}$ & $\begin{array}{c}8.3(4.5) \\
7.1(1.6-29.0)\end{array}$ & $\begin{array}{c}10.2(5.5) \\
9.4(0.5-21.3)\end{array}$ & $.08^{\mathrm{a}}$ \\
\hline Neutrophil count & $\begin{array}{c}5.9(4.5) \\
5.2(0.01-24.6)\end{array}$ & $\begin{array}{c}6.2(4.3) \\
5.1(1.0-24.6)\end{array}$ & $\begin{array}{c}8.5(5.0) \\
8.1(0.01-19.9)\end{array}$ & $.02^{\mathrm{a}}$ \\
\hline Lymphocyte count & $\begin{array}{c}1.5(0.9) \\
1.3(0.2-6.3)\end{array}$ & $\begin{array}{c}1.5(0.8) \\
1.3(0.2-4.8)\end{array}$ & $\begin{array}{c}1.3(1.5) \\
0.9(0.2-6.3)\end{array}$ & $.01^{\mathrm{a}}$ \\
\hline Hemoglobin & $\begin{array}{c}11.9(2.5) \\
12.3(1.1-17.1)\end{array}$ & $\begin{array}{c}12.0(2.7) \\
12.3(1.1-17.1)\end{array}$ & $\begin{array}{c}11.5(2.0) \\
11.9(6.3-14.5)\end{array}$ & $.11^{\mathrm{a}}$ \\
\hline Platelet ${ }^{\star} 1000$ & $\begin{array}{c}215.7(82.9) \\
196.5(44-628)\end{array}$ & $\begin{array}{c}222.9(84.8) \\
201.0(81-628)\end{array}$ & $\begin{array}{l}187.3(69.4) \\
181(44-337)\end{array}$ & $.05^{\mathrm{a}}$ \\
\hline D-dimer & $\begin{array}{c}1694.0(1840.4) \\
1040.0(140-9989)\end{array}$ & $\begin{array}{c}1406.9(1380.9) \\
940.0(140-7965)\end{array}$ & $\begin{array}{c}2832.1(2807.2) \\
1480.0(240-9989)\end{array}$ & $.004^{\mathrm{a}}$ \\
\hline Ferritin & $\begin{array}{c}426.7(734.8) \\
201.5(9-5842)\end{array}$ & $\begin{array}{c}394.5(762.1) \\
186.0(18-5842)\end{array}$ & $\begin{array}{c}539.2(614.1) \\
360.0(9-3173)\end{array}$ & $.004^{\mathrm{a}}$ \\
\hline Mean arterial pressure & $\begin{array}{c}87.0(5.9) \\
87.3(67.7-100.7)\end{array}$ & $\begin{array}{c}87.9(5.2) \\
87.7(76.0-100.1)\end{array}$ & $\begin{array}{c}83.7(7.3) \\
84.7(64.7-98.0)\end{array}$ & $.194^{\mathrm{a}}$ \\
\hline Shock index & $\begin{array}{c}0.73(0.7) \\
0.67(0.1-8.0)\end{array}$ & $\begin{array}{c}0.73(0.72) \\
0.66(0.1-8.0)\end{array}$ & $\begin{array}{c}0.74(0.27) \\
0.73(0.13-1.46)\end{array}$ & $.01^{\mathrm{a}}$ \\
\hline Modified shock index & $\begin{array}{c}0.97(0.21) \\
0.98(0.15-1.73)\end{array}$ & $\begin{array}{c}0.96(0.17) \\
0.97(0.17-1.29)\end{array}$ & $\begin{array}{c}1.07(0.31) \\
1.08(0.15-1.73)\end{array}$ & $.01^{\mathrm{a}}$ \\
\hline Age shock index & $\begin{array}{c}54.3(46.9) \\
49.2(8.2-124.4)\end{array}$ & $\begin{array}{c}48.6(10.9) \\
48.7(8.2-79.2)\end{array}$ & $\begin{array}{c}57.9(22.6) \\
52.5(10.8-124.4)\end{array}$ & $.04^{\mathrm{a}}$ \\
\hline
\end{tabular}

Table 3. ROC analysis results of the modified shock index in predicting mortality

\begin{tabular}{|lccccccc|}
\hline Cut-off value & $\begin{array}{c}\text { AUC } \\
(\mathbf{9 5 \%} \mathbf{C I})\end{array}$ & $\begin{array}{c}\text { Youden } \\
\text { index }\end{array}$ & P value & Sensitivity & Specificity & PPV & NPV \\
\hline $\begin{array}{c}0.658 \\
(0.572-0.738)\end{array}$ & 0.35 & .02 & $55.6 \%$ & $79.4 \%$ & 38.9 & 86.7 \\
\hline ROC, receiver operating characteristic; $\mathrm{AUC}$, area under the curve; $\mathrm{CI}$, confidence interval; PPV, positive predictive value; NPV, negative predictive value \\
\hline
\end{tabular}




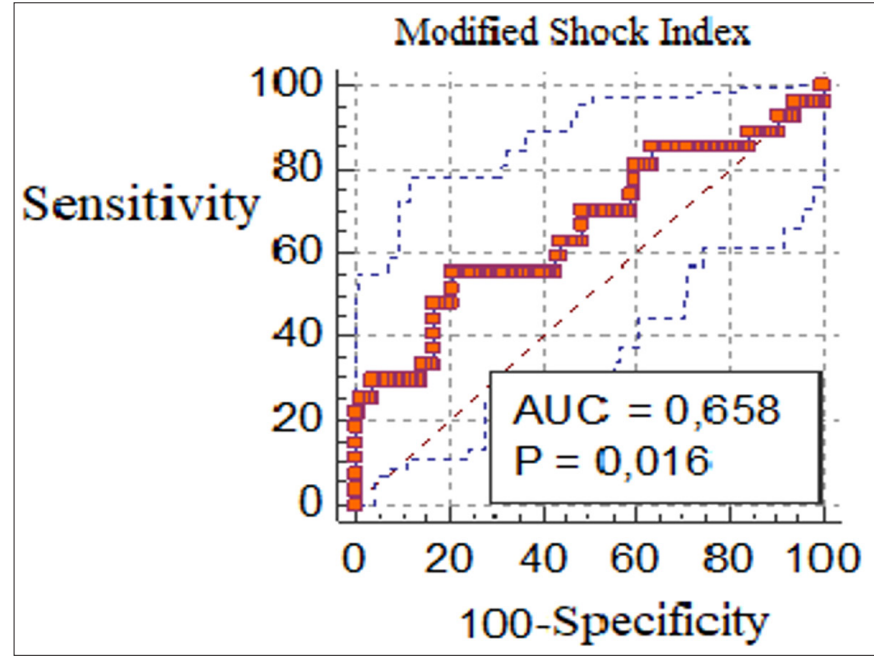

Figure. Receiver operating characteristic curve of the modified shock index

The effect of MSI on the mortality of the patients was examined using the logistic regression analysis after correcting the data according to patient age and body temperature levels which were included in the multivariate model after being determined as significant in the univariate analysis (Table 4). The statistical analysis showed that the cases with higher MSI values were 86 times more likely to result in mortality than those with lower MSI values.

\section{DISCUSSION}

This is the first study in the literature to compare SI, MSI and ASI in terms of their ability to predict mortality in geriatric patients with COVID-19 pneumonia. In addition to the efficacy of these indexes in mortality prediction, we also aimed to determine their superiority over each other, if any. According to our results, MSI was a simple, fast and effective predictor of mortality in advanced-age patients with COVID-19 pneumonia and it was superior to SI and ASI in this respect.

The main target in the pathogenesis of COVID-19 infection is the respiratory system with severe pneumonia (13). Severe pneumonia caused by human coronaviruses results in acute lung damage and ARDS by triggering a cytokine storm as a result of the uncontrolled excess production of cytokines 14 . Increased cytokine release causes dysfunction in all tissues and organs due to the pressure created by inflammation. Vital parameters are almost always the easiest available tools to assess systemic response. Any trauma, infection, tissue and organ disorder that creates stress in the body are objectively reflected by vital parameters in the fastest way. Thus, SI, ASI, and MSI have been derived from these parameters to allow the clinician to predict the severity of the disease. Some studies have determined that SI can be used in many systemic conditions, including sepsis, trauma, pulmonary embolism, and pneumonia $(7,15-17)$.

In studies evaluating all age groups, it has been reported that advanced age is a single risk factor in COVID-19 pneumonia (18). In our study, when age was evaluated alone, a statistically significant difference was found between the non-survivors and survivor groups. In this sense, while ASI is expected to be an effective parameter, it did not show any statistically significant difference between the non-survivors and survivors' groups in the ROC analysis. This unexpected result can be explained by COVID-19 leading to the development of myocarditis, which is an inflammatory disease of the heart presenting with myocardial damage without an ischemic cause (19).

It has been shown that ACE2 expression, which is the main target cell in COVID-19, is particularly high in the lung, heart, ileum, kidney, and bladder (20). While no decrease in ventricular functions is generally observed in cardiac damage due to COVID-19, patients have uncomplicated lymphocytic myocarditis accompanied by normal cardiac functions (21). In more severe cases, patients may present with jugular venous fullness, peripheral edema, and right upper quadrant pain accompanied by signs of right heart failure (21). The right ventricle is considered to have high compliance and low-resistance pulmonary circulation and is suited to adapt to changes in volume rather than pressure (22).

Since the time it was introduced, SI has been used as a more significant parameter in cases of hemorrhagic shock; i.e., presence of a rapid volume change (3). Systemic infection and myocarditis due to COVID-19 more often cause right ventricular hypertrophy and acute insufficiency symptoms, which have higher adaptability to volume changes (23). In this regard, while the systolic pressure and pulse values of patients may be affected later, this pathophysiological point of view supports the results of our study.

\begin{tabular}{|c|c|c|c|c|c|c|c|c|}
\hline & B & SE & Wald & SD & $\mathbf{P}$ & $\operatorname{Exp}(B)$ & 95\% CI Lower & 95\% CI Upper \\
\hline Age & 0.09 & 0.034 & 6.70 & 1 & 0.01 & 1.09 & 1.02 & 1.17 \\
\hline Body temperature & 0.683 & 0.249 & 7.52 & 1 & 0.006 & 1.98 & 1.21 & 3.22 \\
\hline MSI & 4.46 & 1.52 & 8.57 & 1 & 0.003 & 86.146 & 4.36 & 1701.6 \\
\hline Constant & -37.9 & 10.53 & 12.98 & 1 & 0 & 0 & & \\
\hline
\end{tabular}


When calculating MSI, the pulse value is divided by the mean arterial pressure. The mean arterial pressure is a stronger value than other vital parameters and used to evaluate the contraction force of the heart and vasopressor requirement of patients. In our study, a striking finding was that the cases with higher MSI were 86 times more likely to result in mortality than those with lower MSI values.

In our study, the number of patients was limited due to the selection criteria including RT-PCR positivity and a specific age group being examined. This limitation can be avoided by conducting further studies in multiple centers with a prospective and long-term design.

According to the ROC analysis conducted in the current study, SI and ASI were not effective parameters in the prediction of mortality in geriatric patients with COVID-19 pneumonia. Although these two indexes were previously reported to be effective methods in the evaluation of sepsis and other pneumonia cases, our results did not show similar efficacy in COVID-19 pneumonia (24).

\section{CONCLUSION}

MSI is a fast, simple and effective method that can be used to predict mortality during triage in the $\mathrm{ED}$ in geriatric patients with COVID-19 pneumonia confirmed by RT-PCR.

\section{ETHICAL DECLARATIONS}

Ethics Committee Approval: This study was approved by Haydarpaşa Numune Education and Research Hospital Clinical Researches Ethics Committee (Date: 01.03.2021, Decision No: 2021/KK/78).

Informed Consent: Because the study was designed retrospectively, no written informed consent form was obtained from patients.

Referee Evaluation Process: Externally peer-reviewed.

Conflict of Interest Statement: The authors have no conflicts of interest to declare.

Financial Disclosure: The authors declared that this study has received no financial support.

Author Contributions: All of the authors declare that they have all participated in the design, execution, and analysis of the paper, and that they have approved the final version.

\section{REFERENCES}

1. Rohat A, Erdem K, Bahadirli S. Thecomparison of two risk prediction models specific for COVID-19: The Brescia-COVID Respiratory Severity Scale versus the Quick COVID-19 Severity Index. Disaster Med Public Health Prep 2021: 1-17.

2. Rady MY, Smithline HA, Blake H, Nowak R, Rivers E. A comparison of the shock index and conventional vital signs to identify acute, criticalillness in theemergency department. Ann Emerg Med 1994; 24: 685-90.
3. Allgöwer M, Burri C. "Schockindex". Dtsch Med Wochenschr 1967; 92: 1947-50.

4. Althunayyan SM, Alsofayan YM, Khan AA. Shock index and modified shock index as triage screening tools for sepsis. J Infect Public Health 2019; 12: 822-6.

5. Pandit V, Rhee P, Hashmi A, et al. Shock index predicts mortality in geriatric trauma patients: an analysis of the National Trauma Data Bank. J. Trauma Acute Care Surg 2014; 76: 1111-5.

6. McCall SJ, Musgrave SD, Potter JF, et al. The shock index predicts acute mortality outcomes in stroke. Int J Cardiol 2015; 182: 523-7.

7. Sankaran P, Kamath AV, Tariq SM, et al. Are shock index and adjusted shock index useful in predicting mortality and length of stay in community-acquired pneumonia? Eur J Intern Med 2011; 22: 282-5.

8. Liu YC, Liu JH, Fang ZA, et al. Modified shock index and mortality rate of emergency patients. World J Emerg Med 2012; 3: 114.

9. Zarzaur BL, Croce MA, Fischer PE, Magnotti LJ, Fabian TC. New vitals after injury: shock index for the young and age shock index for the old. J Surg Res 2008; 147: 229-36.

10. Jayaprakash N, Gajic O, Frank RD, Smischney N. Elevated modified shock index in early sepsis is associated with myocardial dysfunction and mortality. J Crit Care 2018; 43: 30-5.

11.Levy MM, Rhodes A, Evans LE, et al. COUNTERPOINT: should the Surviving Sepsis Campaign guidelines be retired? No. Chest 2019; 155: 14-7.

12. Nguyen HB, Rivers EP, Knoblich BP, et al. Early lactate clearance is associated with improved outcome in severe sepsis and septic shock. Crit Care Med 2004; 32: 1637-42.

13. Huang C, Wang Y, Li X, et al. Clinical features of patients infected with 2019 novel coronavirus in Wuhan, China. The Lancet 2020; 395: 497-506.

14.Sun $\mathrm{X}$, Wang T, Cai D, et al. Cytokine storm İntervention in the early stages of COVID-19 pneumonia. Cytokine Growth Factor Rev 2020; 53: 38-42.

15. Cannon CM, Braxton CC, Kling-Smith M, et al. Utility of the shock index in predicting mortality in traumatically injured patients. J. Trauma Acute Care Surg 2009; 67: 1426-30.

16. Otero R, Trujillo-Santos J, Cayuela A, et al. Haemodynamically unstable pulmonary embolism in the RIETE Registry: systolic blood pressure or shock index? Eur Respir J 2007; 30: 1111-6.

17. Rousseaux J, Grandbastien B, Dorkenoo A, Lampin ME, Leteurtre S, Leclerc F. Prognostic value of shock index in children with septic shock. Pediatr Emerg Care 2013; 29: 1055-9.

18. Du RH, Liang LR, Yang C-Q, et al. Predictors of mortality for patients with COVID-19 pneumonia caused by SARS-CoV-2: a prospective cohort study. Eur Respir J 2020; 55-5.

19. Esfandiarei M, McManus BM. Molecular biology and pathogenesis of viral myocarditis. AnnuRev Pathol Mech Dis 2008; 3: 127-55.

20.Zou X, Chen K, Zou J, Han P, Hao J, Han Z. Single-cell RNAseq data analysis on the receptor ACE2 expression reveals the potential risk of different human organs vulnerable to $2019-\mathrm{nCoV}$ infection. Front Med 2020: 1-8.

21. Hu H, Ma F, Wei X, Fang Y. Corona virüs fulminant myocarditis treated with glucocorticoid and human immunoglobulin. Eur Heart J 2021; 42: 206.

22. Haddad F, Hunt SA, Rosenthal DN, Murphy DJ. Right ventricular function in cardio vascular disease, part I: anatomy, physiology, aging, and functional assessment of the right ventricle. Circulation 2008; 117: 1436-48.

23. Martínez-Mateo V, Fernández-Anguita MJ, Paule A. Electro cardiographic signs of acute right ventricular hypertrophy in patientswith COVID-19 pneumonia: A clinica lcases eries. J. Electrocardiol 2020; 62: 100-2.

24. Yasaka Y, Khemani RG, Markovitz BP. Is shock index associated with outcome in children with sepsis/septicshock? Pediatr Crit Care Med 2013; 14: e372-e9. 